\title{
Message found in a gravity wave
}

\author{
A blast from the past.
}

I love to think about infinity and the fourth dimension, so I was happy when some cosmologists began saying that our Universe is a pair of infinite hypersheets, or branes, floating in higher-dimensional space. According to the new cyclic universe theory, most of the time the two branes hang out parallel to each other, but every now and then they splat together and fill all of space with light.

I like the space-filling Big Flash a lot better than the old-timey single-point Big Bang, which is way too theophanous for me. That's a fancy word that means 'from the hand of God'. I may not have gone to college, but I read a lot, and I think for myself.

I see the two branes as mates; our home space is like a nurturing mother, fertilized by vivid encounters with her spouse. When they embrace, energy wells up like water from a spring. It must be wonderful. I've never actually had sex myself.

After each flash, the branes are driven asunder by the hateful forces of dark energy. But eventually the spiteful dissipation ends, and the pair trysts again, cycle after cycle, time without beginning or end.

Cosmologists estimate that the most recent Big Splat was 14 billion years ago, and they suppose the next to be a trillion years away. But on this last point, I differ. I have reason to believe the other brane is going to smack into us very soon - which is why I'm out here in Maw's pasture spelling out my message with rocks as fast as I can lug them.

It's an especially hot day, which is a warning sign in itself. The approach of the father brane is diddling the fundamental constants of nuclear fusion, and our Sun is burning brighter than ever before. I'm taking apart a whole stone wall to write this message, this very narrative that you read.

I've tried to get out the word via e-mail and my blog, but nobody takes me seriously. I'm not a legitimate scientist. People dismiss me because I don't have all those fancy initials after my name - and maybe because I live with my mother on the family farm.

I'm curious about how the world works, and I'm clever with electronics. When I'm not doing chores, I run the only computer repair shop in the county. I have a satellite broadband link to the web. I read, or at least skim, every single cosmology paper that appears on the arXiv.org site, and that's nigh on 2,000 papers a year, friend.

When I first learned about the cyclic universe, I was especially thrilled to know there are know there are
infinite numbers of planets. Not only do we have infinitely many planets in this cycle, there were infinitely many of them in the previous cycle, and will be in the next one, and so on. That really ups the odds that somewhere, somewhen, everything is just right. There's an Eden planet with someone like me living there with a pretty wife, and he doesn't have to clean up after any filthy chickens.

Thinking about the Eden world, I began wondering if I might be able to get signals from planets that are fabulously distant in space and time. What if 20 billion years ago, way back in the previous cycle, a planet 20 billion light years away had sent a signal aimed precisely towards my present location?

There is a small problem. Because of that Big Flash 14 billion years ago, we can't hope to receive any coherent radio or TV from more than 14 billion light years away. The energy from the splat would have scrambled any messages. But wait! What about signals in the form of gravitational waves?

I got the idea for my gravity wave detector from a dish of green gelatin salad that Maw had set on the table beside a roast chicken. She was carving up the tough old bird and the green gelatin was shivering, with the little bits of canned fruit jiggling up and down.

Man, it's hot out here hauling rocks beneath our doomed Sun. I'm using five or six stones per letter.

Long story short. I made my gravity wave detector from a bathtub full of green gelatin - my sense was that the particular shade of colour might be important. I scavenged a couple of gyroscopic motion sensors from cameras, sank them into the gelatin, and wired them to a video display so I can see the gelatin jiggles as weird screens. Late at night, when the chickens are asleep and the traffic on the highway dies down, I see messages. Not that it's all that easy to pick the signal from the fuzz. You might say I use my nervous system as the final processing filter. And never mind any no-can-do talk that the last cycle's gravity waves are too stretched out by now to be decipherable. A mind is a powerful thing.

Just like I expected, I found a message from a planet in the last cycle, from a guy like me, but maybe happier. He was passing on the news that the cycle between splats is only 14 billion years and not any trillion, and the collapse is far more abrupt than anyone realized. Good to know. Just to return the favour, I'm sending word into the next cycle - via gravity waves.

Any massive object gives off gravity waves when you move it - which is why I'm spelling out this message with stones. The rocks broadcast gravity waves as I set them into position and, for that matter, they'll keep on sending out waves for a while - because Earth herself is spinning around, at least until she melts into X-rays and Higgs bosons. Which will be pretty soon now, I reckon.

I feel funny all over, as if my molecules are coming apart. And the Sun - it looks bloated and red, like it's filling up half the sky. The cars on the highway must not be working any more, because people are standing at the edge of the pasture pointing at me.

Pretty soon now, the branes are gonna be getting it on. Time for my last words.

I lived, I was real. And the end is coming sooner than you think.

\section{Rudy Rucker}

Rudy Rucker's latest novel Postsingular was published by Tor in 2007. A sequel, Hylozoic, will appear in 2009. 